\title{
Diverse trends in shell weight of three Southern Ocean pteropod taxa collected with Polar Frontal Zone sediment traps from 1997 to 2007
}

\author{
Donna Roberts • William R. Howard • Jason L. Roberts • \\ Stephen G. Bray • Andrew D. Moy • Thomas W. Trull • \\ Russell R. Hopcroft
}

Received: 5 July 2013/Revised: 10 June 2014/ Accepted: 19 June 2014 / Published online: 4 July 2014 (C) The Author(s) 2014. This article is published with open access at Springerlink.com

\begin{abstract}
The impact of ocean acidification on key ocean calcifiers is predicted to be imminent, particularly in highlatitude ecosystems. Long-term field observations are essential to ground truth predictions of change in regional ecosystems. Here, we report on aragonitic pteropods collected to sediment traps at $800 \mathrm{~m}$ depth at $54^{\circ} \mathrm{S}, 140^{\circ} \mathrm{E}$ in the Polar Frontal Zone (PFZ) of the Southern Ocean from 1997 to 2007. Statistically significant trends were not identified in either mass or number flux from 1997 to 2007; however, differences emerged in decadal trends seen in shell weight for each of the three common taxa collected: Limacina helicina antarctica forma antarctica shells
\end{abstract}

D. Roberts $(\bowtie) \cdot$ J. L. Roberts · S. G. Bray .

A. D. Moy · T. W. Trull

Antarctic Climate and Ecosystems Cooperative Research Centre, University of Tasmania, Private Bag 80, Hobart, TAS 7001,

Australia

e-mail: D.Roberts@acecrc.org.au

W. R. Howard

School of Earth Sciences, University of Melbourne, Melbourne, VIC 3010, Australia

J. L. Roberts - A. D. Moy

Department of the Environment, Australian Antarctic Division, Channel Highway, Kingston, TAS 7050, Australia

T. W. Trull

Marine and Atmospheric Research, Commonwealth Scientific and Industrial Research Organisation (CSIRO), Castray

Esplanade, Hobart, TAS 7000, Australia

T. W. Trull

Institute for Marine and Antarctic Studies, University of

Tasmania, Private Bag 129, Hobart, TAS 7001, Australia

R. R. Hopcroft

Institute of Marine Science, University of Alaska Fairbanks,

Fairbanks, AK 99775-7220, USA became significantly lighter $(P<0.05), L$. retroversa australis shells became significantly heavier $(P<0.05)$ and L. helicina antarctica forma rangi shells did not change significantly. These results suggest that factors other than ocean acidification affect pteropod population variations on decadal timescales, with the potential to either amplify or counter the impact of decreasing aragonite saturation state, at least in the short term. Comparison to sea surface temperature and chlorophyll biomass did not identify these as significant drivers of the observed changes, and attribution across these multiple variables requires better understanding of pteropod physiology and ecology. Our PFZ pelagic pteropod observations provide a reference for evaluation of southern polar pteropod responses to changing ocean conditions in coming decades. Importantly, these data also raise the issue of taxonomic care when monitoring the region for impacts of ocean acidification on calcifiers.

Keywords Southern Ocean - Polar Frontal Zone · Sediment traps · Pteropod · Aragonite · Ocean acidification

\section{Introduction}

Due to its large surface area, cold waters, high wind velocity and high export of organic carbon to deeper layers of the ocean, the Southern Ocean is one of the most important regions in the global carbon cycle and has a major effect on global air-to-sea $\mathrm{CO}_{2}$ fluxes (McNeil et al. 2007; Takahashi et al. 2009; Midorikawa et al. 2012). Furthermore, the Southern Ocean represents the largest sink for anthropogenic $\mathrm{CO}_{2}$ in the world ocean (Gruber et al. 2009) with long-term increases in surface water $\mathrm{CO}_{2}$ identified between the subtropical front and the sea-ice 
zone (McNeil et al. 2001; Yoshikawa-Inoue and Ishii 2005; Takahashi et al. 2009; Midorikawa et al. 2012). The increasing oceanic uptake of $\mathrm{CO}_{2}$ by the world's oceans, and in high-latitude regions in particular, gives us cause for concern for the polar calcifying zooplankton as it is now well established that additional oceanic $\mathrm{CO}_{2}$ leads to a reduction in ocean $\mathrm{pH}$ and associated decline in the availability of carbonate to calcifiers in these regions (Fabry et al. 2009) by processes known as ocean acidification (Caldeira and Wickett 2003).

Increasing $\mathrm{pCO}_{2}$ in the surface waters of the Pacific sector of the Southern Ocean south of $50^{\circ} \mathrm{S}$ (estimated to be between 1.8 and $2.7 \mu \mathrm{atm}$ year $^{-1}$ : Takahashi et al. 2009) accompany $\mathrm{pH}$ decreases in the same water masses. Rates of pH change between 1969 and 2003 were between 0.0011 and 0.0013 year $^{-1}$ north of the Polar Front (PF), and more rapid in the Polar Zone (0.0020 year ${ }^{-1}$; Midorikawa et al. 2012). Extrapolating Midorikawa et al.'s (2012) changes into the future, the Polar Zone south of the PF will be undersaturated with respect to aragonite in summer before the end of the century. This is in agreement with ocean carbon cycle model simulations (Orr et al. 2005) that suggest a decrease in surface ocean $\mathrm{pH}$ of at least 0.3 , with accompanying decreases in aragonite saturation, from current conditions by the end of the century. Moreover, projections of aragonite saturation in the Southern Ocean show aragonitic calcifiers could be faced with undersaturated conditions as early as the 2030s in the winter months (McNeil and Matear 2008).

Pteropods, planktonic gastropods with aragonite shells, are common components of polar zooplankton communities and represent a significant conduit for energy transfer in polar pelagic communities through their role in polar food webs, both as consumers of, and prey for, various marine organisms, including commercially important fish (Gilmer and Harbison 1991; Seibel and Dierssen 2003; Hunt et al. 2008; Bednaršek et al. 2012a; Lischka and Riebesell 2012). In addition, they play important roles in the ocean carbon cycle, contributing significantly to vertical fluxes of both organic matter (via faecal pellets and pseudo faeces) and biogenic carbonate (via calcium carbonate shells; Berner and Honjo 1981; Betzer et al. 1984; Byrne et al. 1984; Gangst $\varnothing$ et al. 2008). Pteropod shell production estimates range between 10 and $50 \%$ of the total pelagic carbonate flux worldwide (Berner 1977; Berger 1978; Berner and Honjo 1981; Fabry and Deuser 1991; Bednaršek et al. 2012b). This percentage increases to $>50 \%$ in the deep Southern Ocean south of the PF (Hunt et al. 2008). Sinking shells also provide ballast for other aggregates in the water column (Klaas and Archer 2002), which may accelerate the descent of particulate organic carbon to the deeper ocean (Bednaršek et al. 2012a).
Laboratory studies on polar pteropods (e.g. the subarctic Clio pyramidata: Orr et al. 2005 and the arctic Limacina helicina: Comeau et al. 2009, 2010a) suggest that pteropod shell dissolution will occur rapidly as the Southern Ocean becomes undersaturated with aragonite. As this is projected to occur by the mid-century (Orr et al. 2005; Steinacher et al. 2009) or earlier (McNeil and Matear 2008) in waters south of the PF, the fate of shelled pteropods in Southern Ocean waters is of particular, and increasing, concern as this ocean continues to absorb $\mathrm{CO}_{2}$ (Fabry et al. 2009). As such, we are faced with the question of whether or not pteropods will thrive, cope, adapt or decline. If pteropods undergo significant decreases in abundance, or even complete loss of taxa, this could have significant implications for Southern Ocean biodiversity and ecological processes (Cooley et al. 2009). Recently, Bednaršek et al. (2013) reported a dissolution response of live juvenile southern polar pteropods within their natural environment as a result of exposure to aragonite-undersaturated surface waters, pointing to the vulnerability of polar pteropods to ocean acidification, as suggested by laboratory studies (Orr et al. 2005; Fabry et al. 2009; Comeau et al. 2009).

Despite the expectation that some effects of ocean acidification will be felt first at high latitudes, and concern for aragonitic calcifiers in these regions, there still are very few in situ observations of pteropods in highlatitude waters. Fewer data sets document seasonal or interannual variability. Detecting and attributing the impact of changing ocean carbonate chemistry on at-risk organisms and ecosystems require benchmark records of variability. Here, we examine pteropods collected by sediment traps at $800 \mathrm{~m}$ below the surface above the Southeast Indian Ridge $\left(54^{\circ} \mathrm{S}, 140^{\circ} \mathrm{E}\right)$ in the Polar Frontal Zone (PFZ) of the Southern Ocean. The samples were collected from 1997 to 2007 to document seasonality and interannual variability. This time-series sampling approach contributes to the monitoring and assessment of biological change in these waters in response to changing ocean chemistry conditions.

\section{Regional setting and methods}

Geographic setting and regional carbonate chemistry

Cold, nutrient-rich PFZ waters are bounded to the north by the Sub-Antarctic Front (SAF) and to the south by the PF (Trull et al. 2001a; Fig. 1a). The SAF is characterised by strong latitudinal surface gradients in temperature and salinity. In this sector of the Southern Ocean, the SAF is split into two branches: one at $50-51^{\circ} \mathrm{S}$, coinciding with a decrease in temperature from 8 to $6{ }^{\circ} \mathrm{C}$, and the second at 


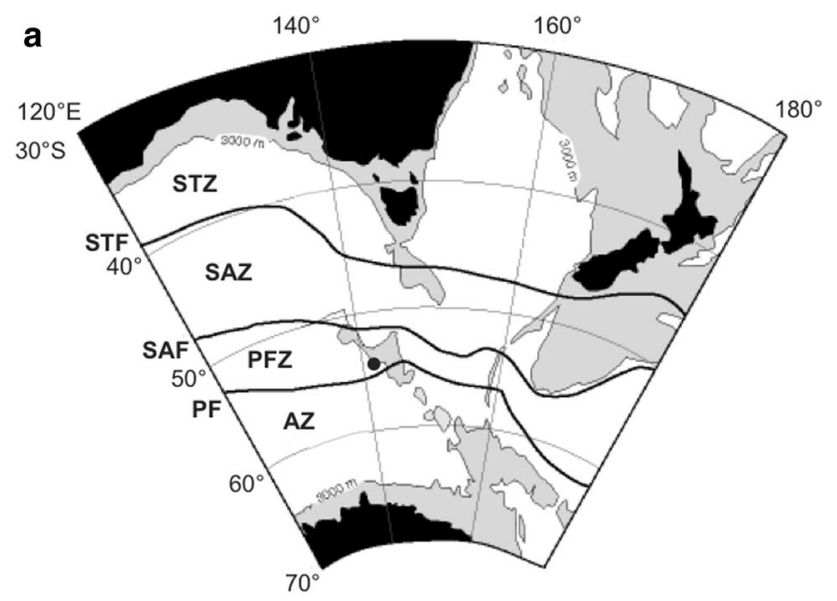

b
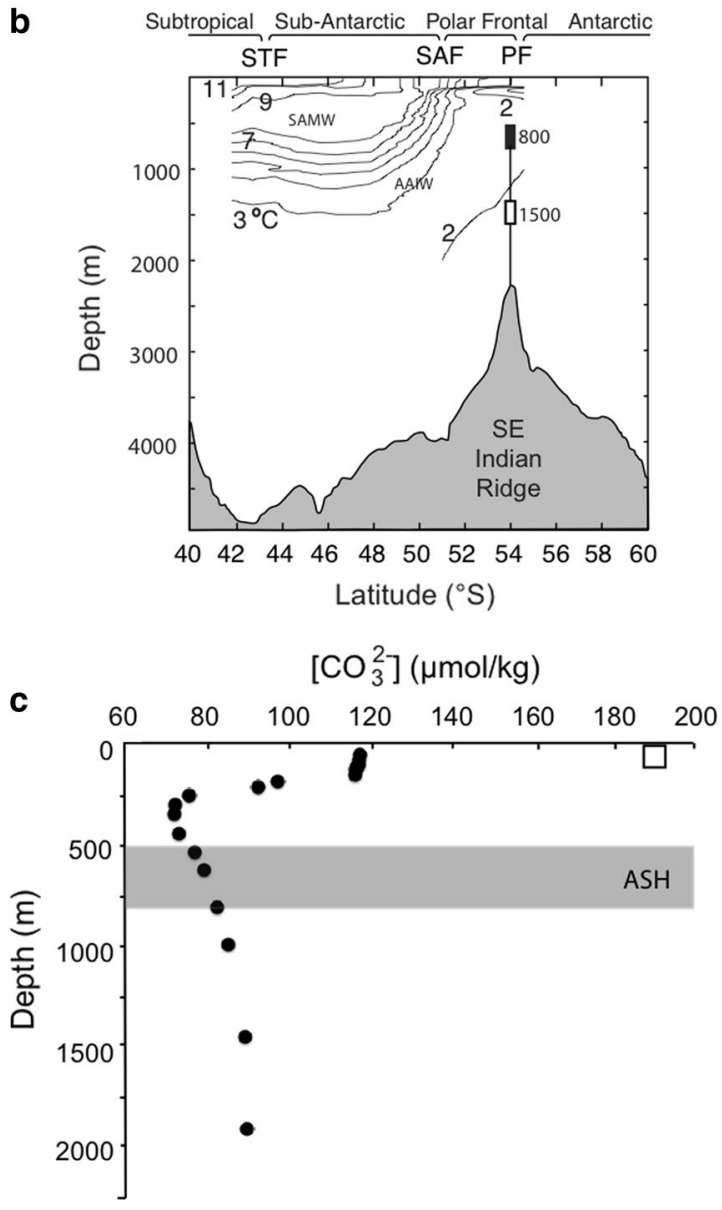

$52-53^{\circ} \mathrm{S}$, coinciding with a decrease in temperature from 6 to $4{ }^{\circ} \mathrm{C}$ (Belkin and Gordon 1996; Sokolov and Rintoul 2002). The PF is also typically split into two branches in this sector: $53-54^{\circ} \mathrm{S}$ and $59-60^{\circ} \mathrm{S}$. The northern branch is generally defined by the equator-ward extent of a subsurface temperature minimum (remnant winter water) usually coinciding with the $2{ }^{\circ} \mathrm{C}$ isotherm, and the southern branch by the latitude where the deeper temperature maximum
4Fig. 1 a Sediment trap mooring location (filled circle) at $54^{\circ} \mathrm{S}, 140^{\circ} \mathrm{E}$ in relation to the oceanographic fronts and zones of the Southern Ocean (after Rintoul and Bullister 1999). STZ Sub-Tropical Zone, STF Sub-Tropical Front, SAZ Sub-Antarctic Zone, SAF Sub-Antarctic Front, $P F Z$ Polar Frontal Zone, $P F$ Polar Front, $A Z$ Antarctic Zone. b Cross section of the sediment trap mooring location (800 $\mathrm{m}$ trapfilled rectangle) in comparison with regional sea floor bathymetry and a late austral summer temperature section of the Southern Ocean along $\sim 140^{\circ} \mathrm{E}$ for the first sediment trap deployment after Trull et al. (Trull et al. 2001a). STF Sub-Tropical Front, SAF Sub-Antarctic Front, $P F$ Polar Front, $S A M W$ Sub-Antarctic mode water, $A A I W$ Antarctic intermediate water. Front and zone locations as they occurred during the first deployment (1997-1998) are marked at the top. Note the presence of the sub-temperature minimum layer marked by the $2{ }^{\circ} \mathrm{C}$ isotherm at the trap site. c Carbonate ion concentration $\left[\mathrm{CO}_{3}{ }^{2-}\right.$ ] profile for $54^{\circ} \mathrm{S}, 140^{\circ} \mathrm{E}$ (closed circles) calculated from total alkalinity, total carbon dioxide, temperature, pressure, salinity, phosphate and orthosilicate using the CO2Sys Excel macro (version 1.02; Lewis and Wallace 1998) and constants from Mehrbach et al. (1973) as modified by Dickson and Millero (1987) after the World Climate Research Programme's project to address climate variability and predictability (CLIVAR) and world ocean circulation experiment (WOCE) SR3 transect between Tasmania and Antarctica in 1998 (voyage AA9706). A preindustrial mixed-layer $\left[\mathrm{CO}_{3}{ }^{2-}\right]$ estimate of $\sim 193 \mu \mathrm{mol} \mathrm{kg}^{-1}$ (open square) was calculated by adding $38 \mu \mathrm{mol} \mathrm{kg}{ }^{-1}$ to modern mixed-layer $\left[\mathrm{CO}_{3}{ }^{2-}\right]$, based on inventories of anthropogenic $\mathrm{CO}_{2}$ in the Southern Ocean (Sabine et al. 2004; Feely et al. 2004). The aragonite saturation horizon (ASH) is estimated to be between $500 \mathrm{~m}$ (from the plotted 1998 data) and $800 \mathrm{~m}$ (from 1994 data reported in Orr et al. 2005) for this region of the Southern Ocean (shaded area)

associated with circumpolar deep water drops below $2.2{ }^{\circ} \mathrm{C}$ (Trull et al. 2001b). Sediment traps were deployed near $54^{\circ} \mathrm{S}, 140^{\circ} \mathrm{E}$ at depths of $\sim 800$ and $\sim 1,500 \mathrm{~m}$ in the PFZ of the Southern Ocean (Fig. 1b), in water depth of $\sim 2,200 \mathrm{~m}$. Surface waters above the mooring site are currently saturated with respect to aragonite (Fig. 1c). Orr et al. (2005) estimated the aragonite saturation horizon (ASH) in this region of the Southern Ocean to be $\sim 800 \mathrm{~m}$, but carbonate ion concentration $\left[\mathrm{CO}_{3}{ }^{2-}\right]$ measurements at the mooring site from the World Climate Research Programme's project to address climate variability and predictability (CLIVAR) and world ocean circulation experiment (WOCE) transect (SR3) between Tasmania and Antarctica suggest the ASH in this region may be $\sim 500 \mathrm{~m}$. In 1998, average surface $(0-100 \mathrm{~m}) \quad\left[\mathrm{CO}_{3}{ }^{2-}\right]$ was $\sim 116 \mu \mathrm{mol} \mathrm{kg}^{-1}$ (compared with an estimated preindustrial value of $\sim 193 \mu \mathrm{mol} \mathrm{kg}{ }^{-1}$; see Fig. 1c for details of preindustrial calculations). Monthly averaged sea surface temperatures (Smith and Reynolds 2004; Fig. 2a top) and chlorophyll-a concentration (Acker and Leptoukh 2007; Fig. 2a bottom) show the interannual variability in the surface temperature and productivity near the mooring site between 1997 and 2007, and surface carbonate parameters averaged in the PFZ over the past 35 years (Midorikawa et al. 2012; Fig. 2b) show increasing $\mathrm{pCO}_{2}$ in the region has led to decreasing $\mathrm{pH}$ and aragonite saturation state 

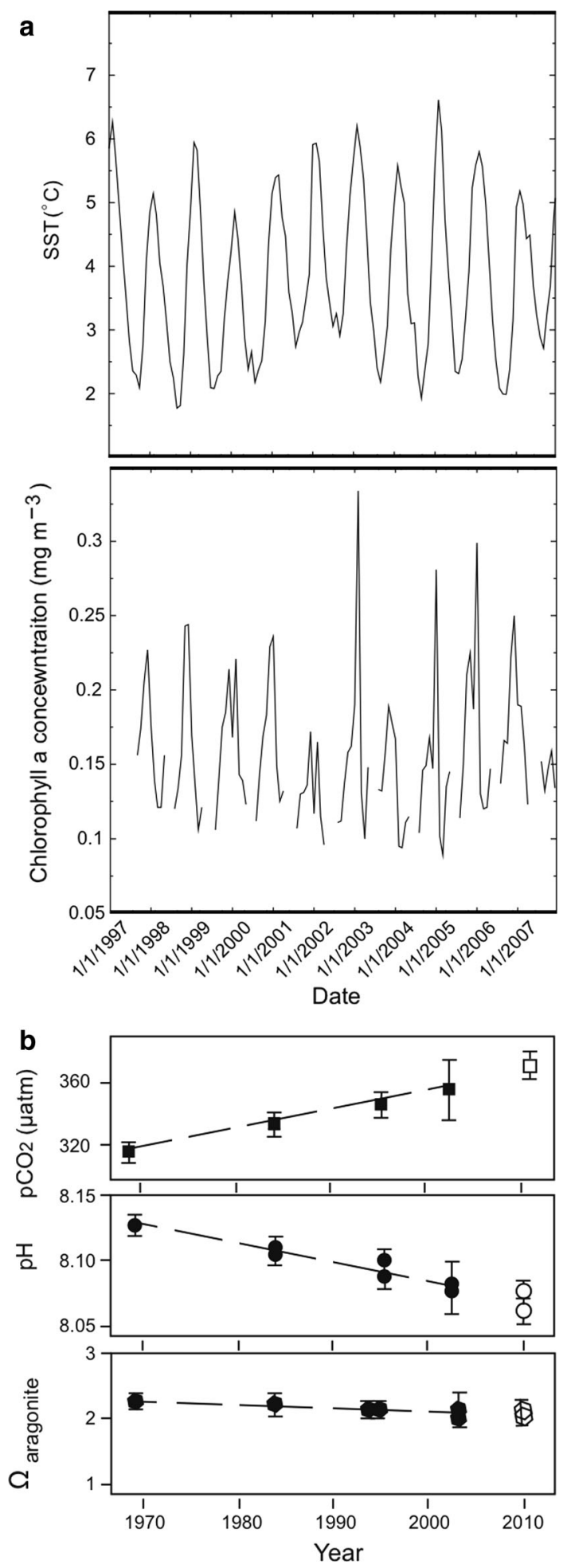

$\left(\Omega_{\text {aragonite }}\right)$. We note though that these mean trends do not take into account the intra- and interannual seasonality of $\mathrm{pCO}_{2}, \mathrm{pH}$ or $\Omega_{\text {aragonite, }}$ which can be large in the Southern Ocean. For example, in the central and eastern Indian Ocean SAZ $\left(41^{\circ} \mathrm{S}\right.$ and $45^{\circ} \mathrm{S}$, respectively), the seasonal
4Fig. 2 a Monthly averages of sea surface temperature (top; Smith and Reynolds 2004) and estimated chlorophyll-a concentration (bottom; Acker and Leptoukh 2007) from 1997 to 2007 at $54^{\circ} \mathrm{S}, 140^{\circ} \mathrm{E}$. b Time series of surface ocean $\mathrm{pCO}_{2} \pm 1 \sigma$ (top) 1969-2003: closed squares and 2009-2010: open squares, $\mathrm{pH} \pm 1 \sigma$ (middle) 1969-2003: closed circles and 2009-2010: open circles and $\Omega_{\text {aragonite }} \pm 1 \sigma$ (bottom) 1969-2003: closed polygons and 2009-10: open polygons averaged from the PFZ over the past 35 years (redrawn from Midorikawa et al. 2012)

amplitude of $\mathrm{CO}_{2}$ is about $50 \mu \mathrm{atm}$ (Borges et al. 2008), which produces as large a variation in aragonite saturation state in a single year as expected for the mean decrease over this period (Fig. 2b). Based on nutrient depletion (the major driver of seasonal aragonite saturation variations), we expect $\sim 1 / 2$ this magnitude of seasonal variations in the PFZ (Lourey and Trull 2001). Interannual variations in mean-annual air-sea $\mathrm{pCO}_{2}$ fluxes are also known to be large in the Southern Ocean, $\sim 25 \%$ of the overall meanannual decadal net uptake rate (Lenton et al. 2013); but may be relatively small in the PFZ where the major mechanism identified for the interannual variations (the Southern Annular Mode of atmospheric pressure variations) has much less modulation than further north in the Sub-Antarctic Zone or further south in Antarctic waters (Lenton and Matear 2007).

Trap deployments and sample retrieval

Southern Ocean sediment trap deployments were initiated in 1997 under the SAZ Project (Trull et al. 2001c) and now continue as a component of the Australian Integrated Marine Observing System Southern Ocean Time Series (Trull et al. 2010). In this paper, we include data from the $54^{\circ} \mathrm{S}, 140^{\circ} \mathrm{E} 800 \mathrm{~m}$ traps for the decade 1997-2007. The Mclane Parflux conical sediment traps (both 21 and 13 cup models were used) collect particles through a $0.5 \mathrm{~m}^{2}$ surface area funnel into a carousel of individual cups that are collected as a time series, with each cup collecting for periods of typically 10 days in summer and as long as 60 days in winter. Sampling frequency analyses showed that January and August were over represented by $1.4 \%$ and October and November were under represented by 2.5 and $1.6 \%$, respectively. The cups were prepared from filtered Southern Ocean sea water amended with $5 \mathrm{~g} \mathrm{~L}^{-1}$ sodium chloride to form a dense brine $(\geq 38.0)$ to minimise washout and diffusion, buffered with $1 \mathrm{~g} \mathrm{~L}^{-1}$ sodium borate to maintain elevated $\mathrm{pH}(\geq 8.0)$ and poisoned with $3 \mathrm{~g} \mathrm{~L}^{-1}$ mercuric chloride to reduce microbial activity (Lee et al. 1992). Full details of mooring designs, site geography, sample processing, archiving and preparation of aliquots are available in Bray et al. (2000) and Trull et al. (2001a). 
Sediment traps are useful for deep-sea and long-term collections and especially useful for the collection of biogenic materials, such as Southern Ocean pteropod aragonite, that is not usually preserved to Southern Ocean sediments. Sediment traps are also particularly useful in preserving the taxonomic integrity of collected specimens when compared with alternative technologies, such as the continuous plankton recorder, which typically allow for only shallow surface water sampling and the preservation of material to genus level. Sediment traps can be, however, complicated by the collection of living pteropods or 'swimmers' (e.g. Harbison and Gilmer 1986), which may bias estimates of downward particle flux. This is because pteropods are diurnal migrators, residing and feeding in surface waters at night and descending to deeper waters during the day. Limacina taxa in particular exhibit the escape behaviour of downward swimming that makes them more susceptible than other pelagic zooplankton to being caught by sediment traps (Gilmer and Harbison 1986). Typical distances travelled are taxon-specific, but for Southern Ocean pteropods are of the order of 50-200 m (Hunt et al. 2008; Comeau et al. 2012), and Hunt et al. (2008) report L. helicina antarctica caught by nets as deep as $500 \mathrm{~m}$. We acknowledge that our sediment traps may contain occasional 'super-swimmers', but we also acknowledge that some individuals may be digested or dissolved before they reach the sediment traps. Accordingly, our reported fluxes may represent an overestimate or underestimate of aragonite flux in the PFZ of the Southern Ocean.

Recovered trap cups were allowed to settle before supernatant was drawn off with a syringe for salinity (which ranged between 38.0 and 46.5) and $\mathrm{pH}$ determinations (which ranged between 8.01 and 8.76), and the remaining sample sieved through a 1-mm sieve (no attempt was made to remove 'swimmers' for the $<1 \mathrm{~mm}$ fraction). The $<1 \mathrm{~mm}$ fraction was then split into ten fractions using a rotating splitter (McLane Inc.; typically $25 \mathrm{~mL}$ each). This 'pteropod aliquot' was soaked in a $3 \%$ hydrogen peroxide solution (buffered to $\mathrm{pH}$ 8.1) for $1 \mathrm{~h}$ to remove organic matter, washed with buffered deionised water $(\mathrm{pH}$ 8.1) and sieved through a $150 \mu \mathrm{m}$ screen. The resulting fraction was dried at $50{ }^{\circ} \mathrm{C}$ overnight and every whole pteropod shell (pitted or fragmented shells were not included in our analyses) picked, identified, enumerated and weighed in taxon-specific batches for each aliquot using a Mettler Toledo microbalance (precision $0.1 \mu \mathrm{g}$ ). We investigated shells in the $150 \mu \mathrm{m}$ to $1 \mathrm{~mm}$ size range as mesoplanktonic pteropods in this size range tend to dominate polar populations (Fabry 1989; Collier et al. 2000) and are likely to be most sensitive to changes in carbonate chemistry (Byrne et al. 1984; Honjo et al. 2008).
Pteropod taxonomy

We follow the species, subspecies and morphotype nomenclature of the marine species identification portal (http://species-identification.org/index.php), i.e. we split $L$. helicina antarctica (LHA) into identifiable antarctic and subantarctic morphotypes: forma antarctica (LHA-A) and forma rangi (LHA-R), respectively.

Interannual averages

For broad comparison purposes only, we calculated the average shell mass flux (Table 1), shell number flux (Table 2) and flux-weighted mean shell weight (Eq. 1) of each taxon (Table 3) for each year between 1997 and 2007. Number flux weighting removes bias generated by collection time differences and allows for interannual comparisons.

$\mathrm{FW}=\sum_{i=1}^{n} c_{\mathrm{i}} \cdot f_{\mathrm{i}} / \sum_{i=1}^{n} f_{\mathrm{i}}$

The flux-weighted average shell weight of each pteropod taxon (FW) is calculated from the average weight (c) of each taxon per cup and the shell flux $(f)$ in terms of shells $\mathrm{m}^{-2}$ day $^{-1}$ based on the number of cups $(n)$ containing the taxon per trap.

\section{Statistical treatments}

As a result of non-uniform cup sampling periods (varying between 5 and 60 days), gaps in our data set and the taxon batch-weighing approach per cup, we are unable to quantify within-sample error distributions. Accordingly, we used a nonparametric statistical test that makes no implicit assumptions about underlying distributions, the two-tailed Spearman's rank correlation coefficient test (Anderson et al. 1981), to detect trends in mass flux (none significant), shell flux (none significant) and shell weight (two of the three taxa show significant trends: Table 4) from the cup data from 1997 to 2007. Significance was assessed using the method of Zar (1972).

The Spearman's rank correlation coefficient test was also used to look for trends in annually averaged sea surface temperature (Smith and Reynolds 2004) and chlorophyll-a concentration (Acker and Leptoukh 2007), an indirect proxy for biomass and primary productivity, between 1997 and 2007 in the PFZ (no significant trends were found). We overlay seasonal (Fig. 4 red solid line) and interannual (Fig. 5 red solid line) trends in $\Omega_{\text {aragonite }}$ for the PFZ and expected calcification rate responses (Fig. 5 red dashed lines) to place our observations in the context of the changes we would expect to see in the region due to ocean acidification alone. 
Table 1 Average shell mass flux $\pm \mathrm{SD}\left(\mathrm{mg} \mathrm{m}^{-2} \mathrm{day}^{-1}\right)$ calculated from the number of cups containing each taxa $(n)$ per trap: Limacina helicina antarctica forma antarctica (LHA-A), Limacina helicina antarctica forma rangi (LHA-R) and Limacina retroversa australis (LRA)

\begin{tabular}{lllll}
\hline Trap & $\begin{array}{l}\text { Average shell mass flux LHA- } \\
\text { A }\end{array}$ & $\begin{array}{l}\text { Average shell mass flux LHA- } \\
\text { R }\end{array}$ & $\begin{array}{l}\text { Average shell mass flux } \\
\text { LRA }\end{array}$ & $\begin{array}{l}\text { No. of days collected per } \\
\text { trap }\end{array}$ \\
\hline $1997 / 1998$ & $0.02 \pm 0.19(2)$ & $0.12 \pm 0.47(6)$ & $0.04 \pm 0.15(4)$ & 153 \\
$1998 / 1999$ & $*$ & $*$ & $*$ & $*$ \\
$1999 / 2000$ & $0.55 \pm 1.10(11)$ & $0.10 \pm 0.31(6)$ & $0.17 \pm 0.17(5)$ & 405 \\
$2000 / 2001$ & $* *$ & $* *$ & $* *$ & $* *$ \\
$2001 / 2002$ & $0.01 \pm 0.08(3)$ & $0.07 \pm 0.30(6)$ & $0.06 \pm 0.13(7)$ & 323 \\
$2002 / 2003$ & $0.04 \pm 0.12(9)$ & $0.41 \pm 0.46(19)$ & $1.20 \pm 1.72(20)$ & 290 \\
$2003 / 2004$ & $0.01 \pm 0.01(6)$ & $0.01 \pm 0.02(5)$ & $0.10 \pm 0.23(11)$ & 378 \\
$2004 / 2005$ & $* * *$ & $* * *$ & $* * *$ & $* * *$ \\
$2005 / 2006$ & $0.02 \pm 0.06(4)$ & $0.04 \pm 0.18(6)$ & $0.06 \pm 0.06(6)$ & 288 \\
$2006 / 2007$ & $0.005 \pm 0.022(5)$ & $0.001 \pm 0.009(3)$ & $0.008(1)$ & 357 \\
\hline
\end{tabular}

* No sample cups 3-12

** Complete trap failure

*** Trap not available for analyses

Table 2 Average shell number flux \pm SD (shells $\mathrm{m}^{-2}$ day $^{-1}$ ) calculated from the number of cups containing each taxa $(n)$ per trap: Limacina helicina antarctica forma antarctica (LHA-A), Limacina helicina antarctica forma rangi (LHA-R) and Limacina retroversa australis (LRA)

\begin{tabular}{lllll}
\hline Trap & $\begin{array}{l}\text { Average shell no. of flux } \\
\text { LHA-A }\end{array}$ & $\begin{array}{l}\text { Average shell no. of flux } \\
\text { LHA-R }\end{array}$ & $\begin{array}{l}\text { Average shell no. of flux } \\
\text { LRA }\end{array}$ & $\begin{array}{l}\text { No. of days collected per } \\
\text { trap }\end{array}$ \\
\hline $1997 / 1998$ & $1 \pm 7(2)$ & $8 \pm 32(6)$ & $1 \pm 4(4)$ & 153 \\
$1998 / 1999$ & $*$ & $*$ & $*$ & $*$ \\
$1999 / 2000$ & $16 \pm 31(11)$ & $5 \pm 18(6)$ & $2 \pm 2(5)$ & 405 \\
$2000 / 2001$ & $* *$ & $* *$ & $2 \pm 2(7)$ & $* *$ \\
$2001 / 2002$ & $0 \pm 5(3)$ & $6 \pm 27(6)$ & $18 \pm 29(20)$ & 323 \\
$2002 / 2003$ & $2 \pm 5(9)$ & $32 \pm 35(19)$ & $1 \pm 2(11)$ & 378 \\
$2003 / 2004$ & $0 \pm 0.4(6)$ & $0 \pm 1(5)$ & $* * *$ & \\
$2004 / 2005$ & $* * *$ & $* * *$ & $1 \pm 1(6)$ & \\
$2005 / 2006$ & $1 \pm 4(4)$ & $3 \pm 13(6)$ & $0.1(1)$ & 357 \\
$2006 / 2007$ & $0.2 \pm 0.8(5)$ & $0.1 \pm 0.3(3)$ & & \\
\end{tabular}

* No sample cups 3-12

** Complete trap failure

*** Trap not available for analyses

\section{Results}

Diversity and abundance

We collected 2,957 pteropod shells in our $54^{\circ} \mathrm{S}, 140^{\circ} \mathrm{E}$ $800 \mathrm{~m}$ sediment trap series from 1997 to 2007. Three $\mathrm{Li}$ macina taxa accounted for $99 \%$ of all shells collected: both morphotypes of LHA: LHA-A and LHA-R and $L$. retroversa australis (LRA; Fig. 3).

Pteropod flux and shell weight

Average total pteropod mass flux ranged from 0.02 to $1.65 \mathrm{mg} \mathrm{m}^{-2} \mathrm{day}^{-1}$ (Table 1), and average total pteropod shell flux ranged from 0.4 to 52 shells $\mathrm{m}^{-2}$ day $^{-1}$ (Table 2). Most of this flux $(>70 \%)$ was captured in summer with autumnal flux decreasing $(22 \%)$ to winter (4\%) and spring minima (3\%). Distinct differences in seasonal weight distribution between the LHA morphotypes and LRA are apparent (Fig. 4). LHA-A and LHA-R show lowest shell weights in winter and highest in autumn and spring. Conversely, LRA shells are heaviest in winter and lowest in summer. Intriguingly, LHA-A shells became significantly lighter $(P<0.05)$, LRA shells became significantly heavier $(P<0.05)$ and LHA-R shells did not change significantly over the decade under investigation (Table 4; Fig. 5). We overlay the seasonal (Fig. 4 red solid line) and interannual (Fig. 5 red solid line) trend in 
Table 3 Number flux-weighted (FW) average shell weight \pm SD $(\mu \mathrm{g})$ calculated from the number of cups containing each taxa $(n)$ per trap: Limacina helicina antarctica forma antarctica (LHA-A), Limacina helicina antarctica forma rangi (LHA-R) and Limacina retroversa australis (LRA)

\begin{tabular}{lllll}
\hline Trap & $\begin{array}{l}\text { FW average shell weight } \\
\text { LHA-A }\end{array}$ & $\begin{array}{l}\text { FW average shell weight } \\
\text { LHA-R }\end{array}$ & $\begin{array}{l}\text { FW average shell } \\
\text { weight LRA }\end{array}$ & $\begin{array}{l}\text { No. of days collected } \\
\text { per trap }\end{array}$ \\
\hline $1997 / 1998$ & $29.2 \pm 2.0(2)$ & $14.3 \pm 2.3(6)$ & $42.9 \pm 15.5(4)$ & 153 \\
$1998 / 1999$ & $*$ & $*$ & $*$ & $*$ \\
$1999 / 2000$ & $34.9 \pm 15.7(11)$ & $18.6 \pm 3.9(6)$ & $56.4 \pm 39.3(5)$ & 405 \\
$2000 / 2001$ & $* *$ & $* *$ & $* *$ & $* *$ \\
$2001 / 2002$ & $17.8 \pm 1.9(3)$ & $11.6 \pm 1.1(6)$ & $24.6 \pm 10.1(7)$ & 323 \\
$2002 / 2003$ & $19.9 \pm 15.7(9)$ & $12.9 \pm 3.7(19)$ & $59.5 \pm 42.2(20)$ & 290 \\
$2003 / 2004$ & $23.9 \pm 9.3(6)$ & $12.5 \pm 2.8(5)$ & $91.9 \pm 42.0(11)$ & 378 \\
$2004 / 2005$ & $* * *$ & $* * *$ & $* * *$ & $* *$ \\
$2005 / 2006$ & $17.4 \pm 11.5(4)$ & $12.5 \pm 2.6(6)$ & $77.2 \pm 26.5(6)$ & 288 \\
$2006 / 2007$ & $22.6 \pm 7.2(5)$ & $11.2 \pm 6.5(3)$ & $75.0(1)$ & 357 \\
\hline
\end{tabular}

* No sample cups $3-12$

** Complete trap failure

*** Trap not available for analyses

Table 4 Limacina helicina antarctica forma antarctica (LHA-A), Limacina helicina antarctica forma rangi (LHA-R) and Limacina retroversa australis (LRA) shell weight $(\mu \mathrm{g})$ trends from sediment traps deployed at $54^{\circ} \mathrm{S}, 141^{\circ} \mathrm{E}$ in the Southern Ocean 1997-2007

\begin{tabular}{llll}
\hline Species & $n$ & $R_{\mathrm{s}}$ & $P$ \\
\hline LHA-A & 40 & $\mathbf{- 0 . 3 2 2}$ & $\mathbf{0 . 0 4 3 0}$ \\
LHA-R & 51 & -0.257 & 0.0686 \\
LRA & 54 & $+\mathbf{0 . 5 7 0}$ & $\mathbf{7 . 2 2 \times 1 0 ^ { - 6 }}$ \\
\hline
\end{tabular}

Spearman's rank correlations $\left(R_{\mathrm{s}}\right)$ are based on the test of the change in weight of the shells of each taxa collected to the trap series over time where $n$ is the number of occurrences per taxa in the data set and $P$ is the level of significance. Significant trends (at the $95 \% \mathrm{CI}$ ) are represented in bold

$\Omega_{\text {aragonite for our sediment trap site to show the change }}$ expected as a result of ocean acidification alone in the region.

\section{Discussion}

Global pteropod biomass has been estimated at $500 \mathrm{Tg} \mathrm{C}$ with the lowest values reported in equatorial waters and the highest values in polar waters: biomass in excess of $100 \mathrm{mg} \mathrm{C} \mathrm{m}^{-3}$ is only found in epipelagic waters (between $200 \mathrm{~m}$ and the surface; Bednaršek et al. 2012b). The epipelagic Southern Ocean mesozooplankton community is dominated by LHA in antarctic waters and LRA in subantarctic waters (Hunt et al. 2008). We collected both of these species (including their morphotypes) in PFZ sediment traps at $800 \mathrm{~m}$ between 1997 and 2007.
The two distinct morphotypes of LHA account for three quarters of the shells collected to our trap series (LHA-R a quarter and LHA-A half of all shells). Van der Spoel et al. (van der Spoel et al. 1997) report LHA-R to be eurythermic and therefore able to tolerate a wider range of temperatures (from 6 to $16^{\circ} \mathrm{C}$ in the Southern Ocean). Conversely, LHA-A is known to be stenothermic and only capable of surviving within a much narrower temperature range ( -0.4 to $4.0^{\circ} \mathrm{C}$ or rarely up to $7^{\circ} \mathrm{C}$ : van der Spoel et al. 1997). Accordingly, LHA-R is thought to be typical of waters north of the PF (Be' and Gilmer 1977; van der Spoel and Dadon 1999), while LHA-A is typical of waters south of the PF (Ramsay 1977; van der Spoel and Dadon 1999). LRA account for the remaining quarter of all shells collected to our trap series. This taxa was reported as one of the most common pteropods between $50^{\circ} \mathrm{S}$ and $60^{\circ} \mathrm{S}$ (van der Spoel et al. 1997), and we have found it to be the most abundant pteropod in subantarctic zooplankton net sample collections (Howard et al. 2011).

Average total pteropod mass flux per trap ranged from 0.02 to $1.65 \mathrm{mg} \mathrm{m}^{-2}$ day $^{-1}$ (Table 1 ), and average total pteropod shell flux ranged from 0.4 to 52 shells $\mathrm{m}^{-2}$ day $^{-1}$ (Table 2). Both measures can be considered to be proxies for abundance of pteropods in PFZ waters. The PFZ values were much lower than the pteropod flux reported from SAZ traps: $0.17-4.99 \mathrm{mg} \mathrm{m}^{-2}$ day $^{-1}$ (Roberts et al. 2011) and for Arctic pteropods: $12-120$ shells $\mathrm{m}^{-2}$ (Lischka and Riebesell 2012) and $<20$ to $\sim 870$ specimens $\mathrm{m}^{-2}$ day $^{-1}$ (Bauerfeind et al. 2014), but there was no significant change in total pteropod mass flux or shell flux in the region from 1997 to 2007. 
Fig. 3 Common polar pteropods: a Limacina helicina antarctica, b Limacina helicina antarctica forma antarctica, c Limacina helicina antarctica forma rangi, d Limacina retroversa retroversa and e Limacina retroversa australis. Scale bars $1 \mathrm{~mm}$. Note 1: Limacina helicina antarctica forma antarctica (b) has a very depressed spire and prominent striation, whereas Limacina helicina antarctica forma rangi (c) has a less depressed spire and no, or faint, striation. Note 2: the subantarctic Limacina retroversa australis (e) is slightly smaller with a more highly coiled spire than the subarctic Limacina retroversa retroversa $(\mathbf{d})$. We collected all but (d) in our $54^{\circ} \mathrm{S}, 140^{\circ} \mathrm{E}$ $800 \mathrm{~m}$ trap series from 1997 to 2007
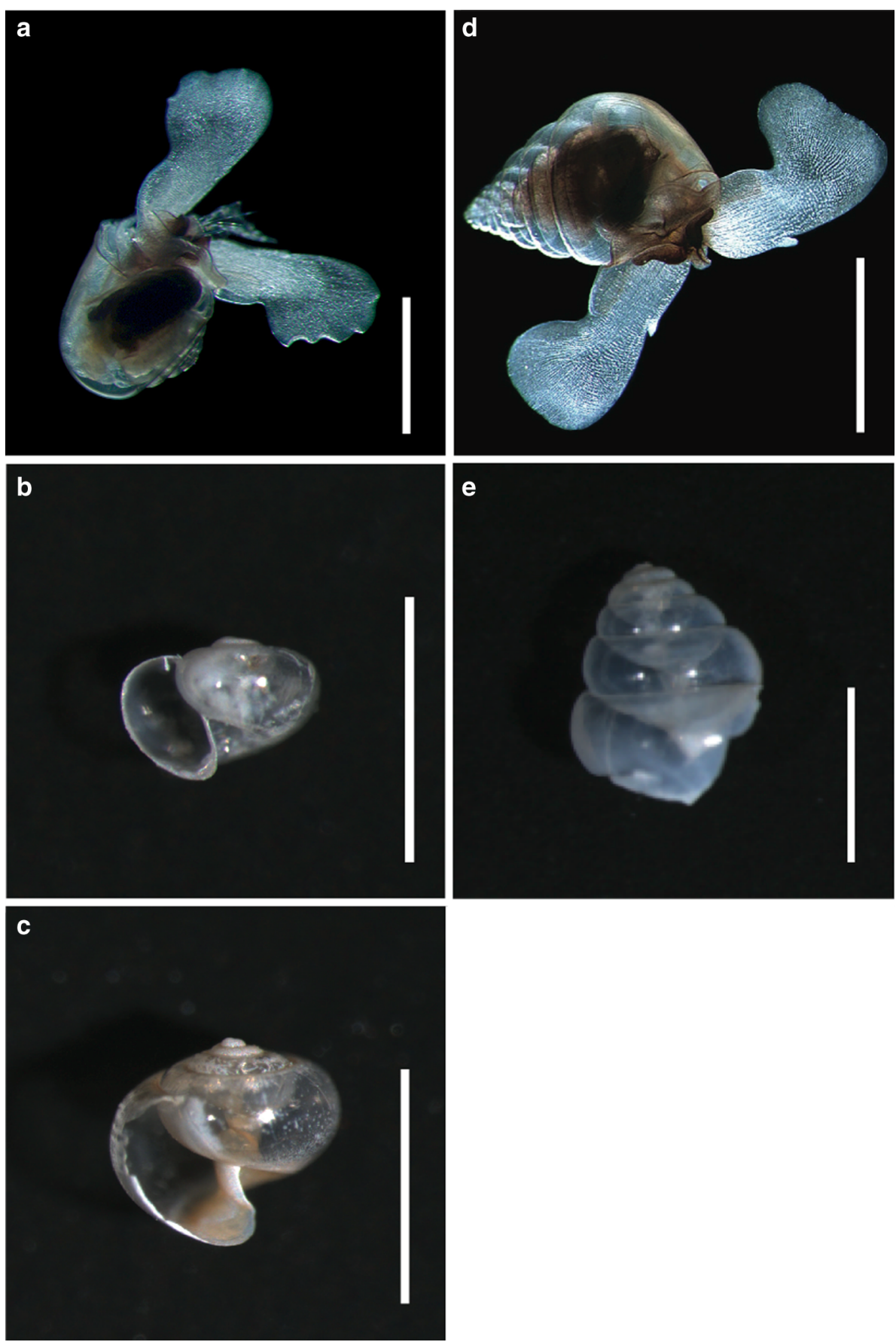

Van der Spoel and Dadon's (1999) hypothesis that antarctic and subantarctic pteropods show different generation modes and seasonal differences in growth rates (with antarctic pteropods producing one generation per year and subantarctic pteropods reproducing twice per year) were confirmed herein by the marked difference in seasonally distributed shell weight between the morphotypes of LHA and LRA (Fig 4). All three taxa were present in PFZ waters year round, but the LHA morphotype shells are lightest over the winter and the LRA shells are heaviest in winter.
The autumn drop off in LHA-A and LHA-R shells may be due to their proposed 1-year life cycle with summertime reproduction (Hunt et al. 2008). Alternatively, it may be the result of a combination of environmental and behavioural factors rather than representing the termination of the life cycle (Bednaršek et al. 2012a). It is thought that LRA has a two-generation per year life cycle, one generation born in early spring, reproducing in late summer and a second growing during autumn, reproducing in spring (van der Spoel and Dadon 1999). As one generation of 


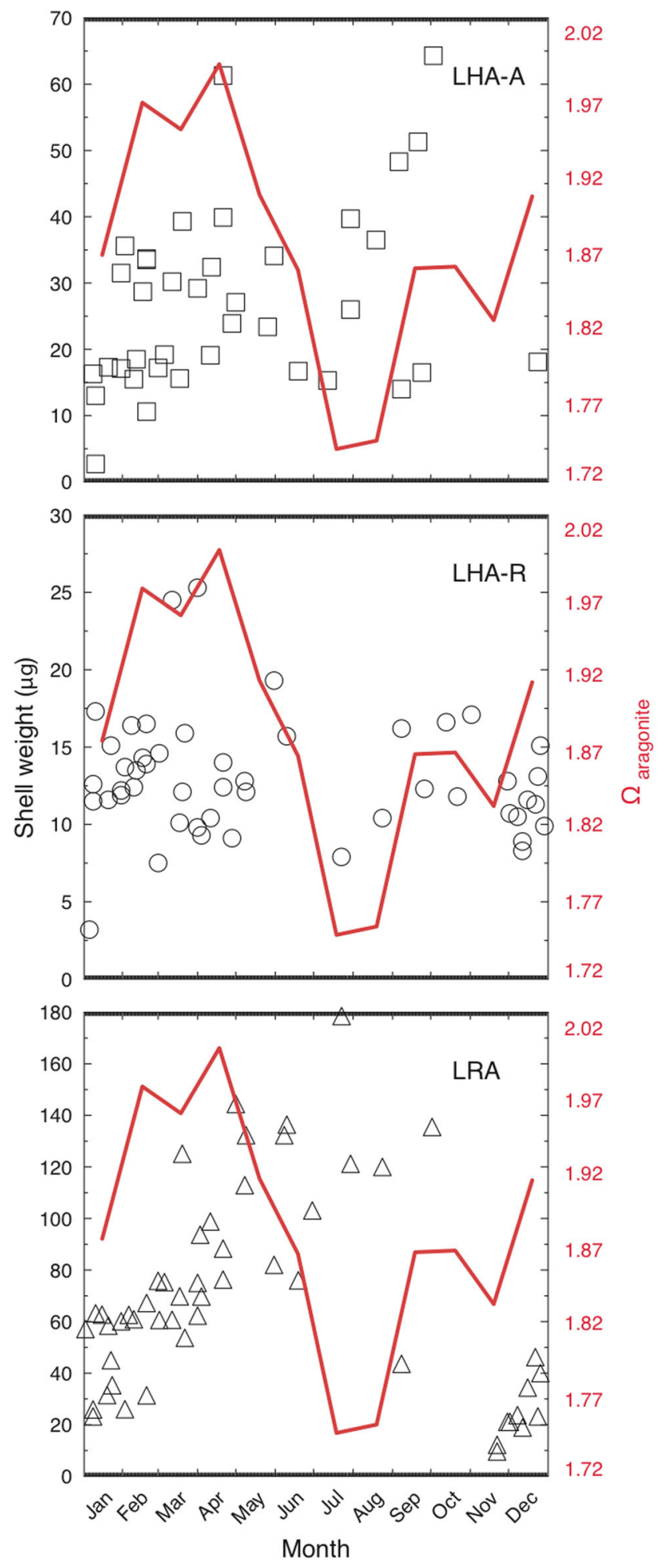

LRA are able to maintain growth over winter (Dadon and de Cidre 1992), whereas LHA die off (Hunt et al. 2008); this is reflected in the different winter-time weight distributions of shells collected to our traps (Fig. 4). Although the role of pteropods is well recognised in polar ecosystems (Hunt et al. 2008; Comeau et al. 2009), fundamental details
4Fig. 4 Weight $(\mu \mathrm{g})$ of pteropod shells collected to $800 \mathrm{~m}$ sediment trap cups in the PFZ from 1997 to 2007 plotted per cup by month. Each data point represents the average shell weight of the taxon under investigation for each sediment trap cup where LHA-A is Limacina helicina antarctica forma antarctica, LHA-R is Limacina helicina antarctica forma rangi and LRA is Limacina retroversa australis. The seasonal pattern of aragonite saturation state $\left(\Omega_{\text {aragonite }}\right)$ at $54^{\circ} \mathrm{S}$, $140^{\circ} \mathrm{E}$ (red line) was estimated from the empirical relationships between DIC and alkalinity (derived by McNeil et al. 2007), using seasonal climatologies of temperature, salinity, dissolved oxygen, silicate, phosphate and nitrate (World Ocean Atlas 2012) and following CO2Sys Excel macro (version 1.02; Lewis and Wallace 1998) and constants from Mehrbach et al. (1973) as modified by Dickson and Millero (1987)

of species-specific life-cycle strategies remain unknown (Bednaršek et al. 2012a). This remains a significant deficiency as it is known that strong seasonality increases the vulnerability of early life stages of pteropods (Seibel and Dierssen 2003; Bernard and Froneman 2009; Bednaršek et al. 2012b). Under high-emission scenarios, projections for the Southern Ocean suggest that by 2100, the ASH will shoal to the surface, exposing pteropods to aragoniteundersaturated waters all year throughout the water column (Orr et al. 2005; Comeau et al. 2012). This could happen as early as the 2030s in winter (McNeil and Matear 2008) exposing Southern Ocean pteropods to seasonal aragonite undersaturation in the near future. Such seasonal undersaturation would make those Southern Ocean pteropods that carry out much of their calcification in winter vulnerable.

The differing trends in shell weight from 1997 to 2007 show the complexity of taxon-specific responses to variability in ocean conditions in the PFZ over the decade: the common PFZ pteropod, LHA-A, is growing increasingly lighter shells $(P<0.05)$; the common SAZ pteropod, LRA, is growing increasingly heavier shells $(P<0.05)$; and shells of LHA-R, typical of waters north of the PF, are not significantly changing (Fig. 5). Overlaying aragonite saturation state ( $\Omega_{\text {aragonite }}$ ) changes for the region from 1997 to 2007 (Fig. 5 red solid line), we can place our observations in the context of the changes we would expect to see in pteropods in the region due to ocean acidification alone. The significant decline in shell weight seen in LHAA shells is greater than the reduction in calcification we would expect to see due to the decline in aragonite saturation state in the region alone. Whilst not significant, the small trend in shell weight for LHA-R is more in keeping with what we would expect to see due to the aragonite saturation state change in the region. In direct contrast to the other two taxa, the significant increasing trend in LRA shell weight goes against the response expected due to ocean acidification alone.

The decrease in LHA-A shell weights appears to be due to other stressors beyond ocean acidification alone. The 

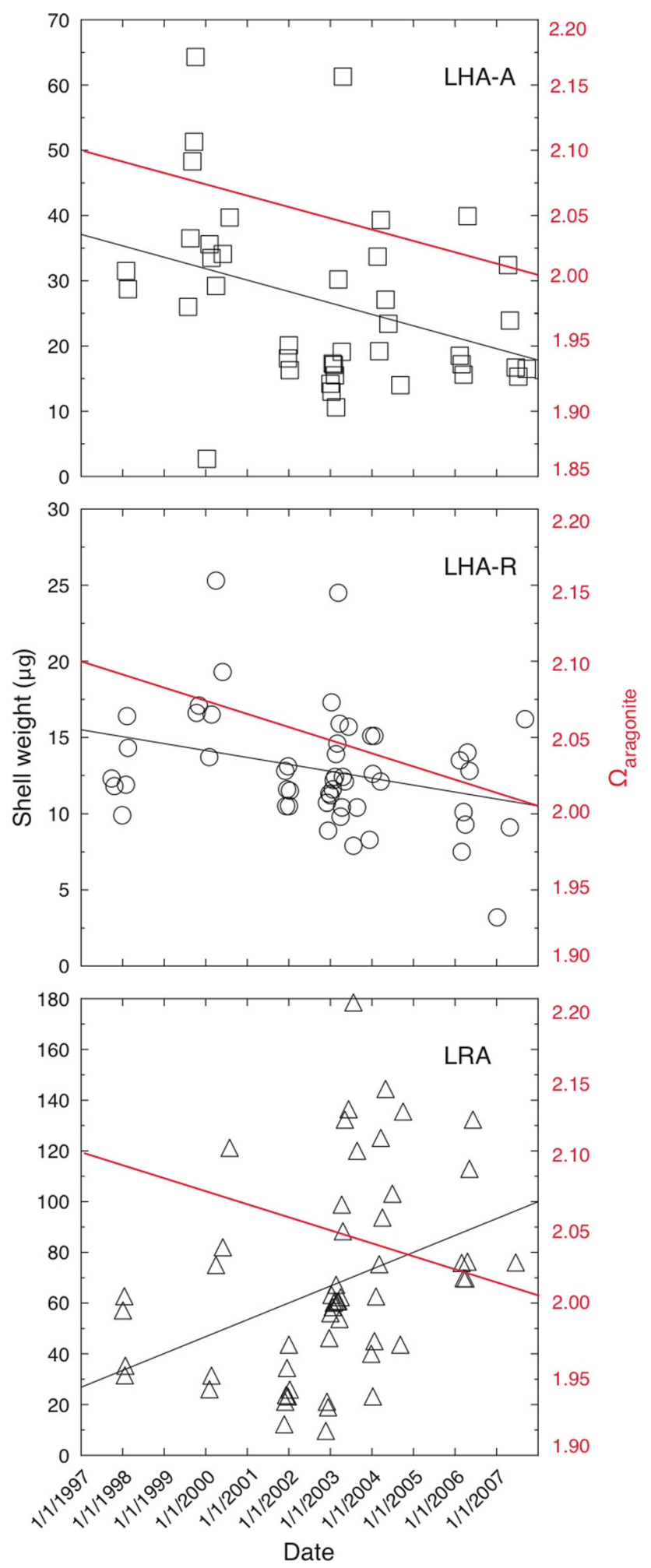

hypothesised consequence of continuing shell loss in LHAA, the most common PFZ taxa (accounting for half of all shells collected to the PFZ trap series), is an increased vulnerability to predation and infection, which would in
4 Fig. 5 Weight $(\mu \mathrm{g})$ of pteropod shells collected to $800 \mathrm{~m}$ sediment trap cups in the PFZ plotted per cup from 1997 to 2007. Each data point represents the average shell weight of the taxon under investigation for each sediment trap cup where LHA-A is Limacina helicina antarctica forma antarctica, LHA-R is Limacina helicina antarctica forma rangi and LRA is Limacina retroversa australis. The linear trend observed in shell weight (grey line) and average aragonite saturation state $\left(\Omega_{\text {aragonite }}\right)$ change in the PFZ from 1997 to 2007 (red solid line) is included (redrawn from Midorikawa et al. 2012) to show the expected linear rate of change in the region as a result of ocean acidification alone compared with the changes observed

turn affect other parts of the food web (Hunt et al. 2008; Comeau et al. 2010b; Bednaršek et al. 2013). Continued shell loss would also lower the rate of vertical carbon flux, as the shells become less dense and less able to act as ballast for other particulate material (Betzer et al. 1984; Francois et al. 2002; Bednaršek et al. 2013). In the Arctic, shell-less L. helicina are not known to have ever existed or to be expected to survive (Comeau et al. 2012). In the Antarctic, we have no experimental data for this taxon to draw conclusions from. Clearly, the causal mechanisms of shell weight loss in LHA-A need to be determined to clarify the likely impact of continuing ocean acidification (and other stressors) in the PFZ on their abundance.

Whilst LHA-R shell weights are not significantly changed over the decade under investigation, the lightest shells are in the later trap cups (Fig. 5) and the small decreasing trend in weight is in keeping with the aragonite saturation state trend in the region. Again, we have no experimental data to draw from for this taxon. Indeed, often LHA-A and LHA-R are lumped together under the LHA species label. Cleary, longer term sediment trap collections and targeted laboratory experiments on the taxon-specific responses to changing acidity [and other stressors as per Lischka and Riebesell (2012) for Arctic pteropods] are required urgently for Southern Ocean pteropods to be able to make definitive statements about the impact of ocean acidification on these polar calcifiers.

Intriguingly, LRA shells increased significantly in mass over the period from 1997 to 2007. LRA are common in the SAZ. We hypothesise that this taxon may be better able to adapt to change as a result of its wider thermal tolerance than the polar LHA-A, but we reiterate that we did not find a significant increase in sea surface temperature concomitant with the heavier LRA shells in our trap series to confirm this hypothesis. In the Arctic, Lischka and Riebesell (2012) found that the wider thermal tolerance of the subarctic $L$. retroversa $\left(2-19^{\circ} \mathrm{C}: \mathrm{Be}^{\prime}\right.$ and Gilmer 1977) compared with the thermal tolerance of the arctic L. helicina $\left(-0.4\right.$ to $7{ }^{\circ} \mathrm{C}$ : van der Spoel 1967) allowed it to shift biomes when faced with ocean acidification and ocean warming stressors. Similarly, Bauerfiend et al. (2014) report changes in the prevalent Arctic pteropod taxa in response to temperature in 
long-term (2000-2009) observatory sediment traps at $79^{\circ} \mathrm{N}$, $4^{\circ} \mathrm{E}$ in the eastern Fram Strait $(200-300 \mathrm{~m})$. At the beginning of their time series, $L$. helicina dominated, whereas $L$. retroversa was only occasionally found in large quantities. This completely changed after 2005/2006 when L. retroversa became the dominant pteropod collected. Concomitant to this shift in species composition, an increase in temperature of the northward-flowing Atlantic Water was recorded (Walczowski and Piechura 2007; BeszczynskaMöller et al. 2012). Again, longer term collections are required to be able to make definitive statements about why this taxon appears to be resistant to ocean acidification (and other stressors?) in this region.

Whatever the mechanism(s), the diversity of calcification trends within the one genus underscores the complexity of species responses to changing ocean conditions and highlights the need for targeted laboratory studies in concert with continued monitoring programs to understand the causal mechanisms for taxon-specific responses to changing ocean conditions. Our observations suggest that the impact of changing ocean acidity on pteropods will be more varied in situ than projected from models and laboratory-based observations. Accordingly, long-term monitoring remains crucial in light of expected changes in chemistry and their potential impacts.

The paradox we observe in calcifier shell weight response to ocean acidification is also seen in the calciticshelled coccolithophore Emiliania huxleyi. The majority of research to date on this species have shown a decrease in coccolith weight (associated with a reduction in calcification) at increased $\mathrm{CO}_{2}$ concentrations in culture experiments, but response is variable between species strains (Riebesell et al. 2000; Langer et al. 2009; De Bodt et al. 2010). Until very recently (Meier et al. 2014), the impact of ocean acidification on Emiliania huxleyi calcification had not been documented in situ. Meier et al.'s (2014) sediment trap study in the Mediterranean Sea reported a response to ocean acidification in the natural assemblage from 1993 to 2005. This assemblage is very likely to represent more than one genotype of Emiliania huxleyi (Read et al. 2013). They concluded the change in coccolith weight was due to both physiological responses, i.e. a decrease in calcification, and morphotype selectivity within the species. Again, future work is needed to distinguish the processes of calcification response to ocean acidification for reliable projections of how calcifying taxa are likely to respond to ongoing ocean acidification.

Taken together, the diversity in pteropod taxon shell weight trends identified herein suggests ocean acidification was not a dominant driver of pteropod population change in the PFZ in the decade from 1997 to 2007. This raises several questions: if not ocean acidification, what are the causes of the diversity of trends observed in shell weight?
LRA may be shifting poleward, consistent with forecast zoogeographic displacement in response to progressive global warming; changes in Southern Ocean pteropods in the PFZ may be related to the phenotypic history of the taxa in question, and/or on a combination of stressors such as temperature, salinity, hypoxia and food availability, as well as $\mathrm{CO}_{2}$ (as suggested by Gazeau et al. 2013). Mackas and Galbraith (2011 )raise an important caveat related to the interpretation of in situ pteropod time-series data: the main concerns about ocean acidification are for what will happen to ocean biota post 2050 or 2100 and, as such, the conclusion that we have not yet passed a threshold does not mean that we will not do so in the near (e.g. 2030: McNeil and Matear 2008) or moderately distant (e.g. 2100: Orr et al. 2005) future. The continued maintenance of pteropod time series in regions particularly at risk of ocean acidification, such as ours, is crucial in order to catch the tipping point(s) for at-risk species.

The longest time series available for zooplankton observations covers the past 60 years and while not as valuable as palaeo-records for long-term observations, they do cover the period in which the effects of acidification are likely to have been largest (Mackas and Galbraith 2011). As yet, a clear trend attributable to the impact of ocean acidification on in situ pteropod populations has not been documented, although some researchers have noted declining abundances of some taxa: Mackas and Galbraith (2011) report a decline in the abundance of Limacina spp. around Vancouver Island, but also report increases in the abundance of Clio spp. in the same time series. In the absence of palaeo-records for pteropods, particularly in polar regions, long-term observation programs and sediment traps remain the best monitoring protocols we have, especially for difficult to access remote locations such as the PFZ. At present, longer term information is still rare but absolutely necessary to document potential biogeochemical and ecosystem changes in high-latitude waters.

\section{Conclusions}

The observations we report for the PFZ for the period 1997-2007 are too short to make definitive statements about the attribution of trends to ocean acidification alone. Moreover, we saw conflicting seasonal and interannual trends in pteropod shell weight over the decade. LHA morphotype shells are heaviest in autumn and spring with a marked drop over the winter. Conversely, LRA shells are heaviest in winter. These observations raise questions about the winter survival strategies of LRA compared with LHA morphotypes and the mechanisms that account for the differences in shell weights in the same water mass for 
aragonite organisms in winter. From 1997 to 2007, we see the complexity of taxon-specific responses to changing ocean conditions in the PFZ: LHA-A is producing increasingly lighter shells $(P<0.05)$, LRA is producing increasingly heavier shells $(P<0.05)$ and LHA-R shells are not significantly changing. Thus, it may be that LHA$\mathrm{A}$ is at greater risk from continuing ocean acidification in the PFZ, although deeper physiological and ecological understanding is required to evaluate this risk. The shell weight trends reported herein suggests that ocean acidification is not yet a driver of PFZ pteropod population change. Whatever the mechanisms, the diversity of calcification trends within the one genus underscores the complexity of species responses to changing ocean conditions. This highlights the need for continued monitoring programs and laboratory experiments to enable detection and attribution of pteropod population changes. Sediment trap time series like the one presented here need to be extended further to clarify the causal mechanisms of pteropod seasonality in Southern Ocean waters and to determine the likely impacts of continuing ocean acidification in the PFZ on their abundance.

Observations and the projections for wintertime aragonite undersaturation as early as the 2030s for the Southern Ocean present a possible risk to calcification for LHA-A in PFZ waters in the future. Accordingly, the value of longterm observations on in situ pteropod populations will increase in the coming decades, particularly in regions where long-term palaeo-observations are unavailable and ocean acidification is predicted to be severe. These will be of most value if supported by targeted taxon-specific laboratory research on polar pteropod reproduction, physiology, thermal tolerance, shell structure, growth and survival in high $\mathrm{CO}_{2}$ waters. As a consequence, we echo the call by Fabry et al. (2009) for urgent and increased efforts in ocean acidity research and long-term monitoring in polar and subpolar seas and Bauerfeind et al. (2014) for urgently needed long-term studies on the occurrence of pteropods for establishing the baseline against which projected changes can be assessed.

Acknowledgments This work by the Australian Government through the Department of Climate Change and Energy Efficiency, Australian Cooperative Research Centres Program, the Australian Antarctic Sciences program (AAS \# 1156) and the Australian Marine National Facility. Chl-a analyses and visualizations used in this paper were produced with the Giovanni online data system, developed and maintained by the NASA GES DISC. We thank three anonymous reviewers for their comprehensive reviews, which greatly enhanced the final manuscript.

Open Access This article is distributed under the terms of the Creative Commons Attribution License which permits any use, distribution, and reproduction in any medium, provided the original author(s) and the source are credited.

\section{References}

Acker JG, Leptoukh G (2007) Online analysis enhances use of NASA earth science data. Eos: transactions American geophysical union 88:14-17. Data: http://disc.sci.gsfc.nasa.gov/giovanni (MODIS Aqua seaWIFS $9 \mathrm{~km}$ grid monthly chl-a climatology on a 2-degree longitude by 1 degree latitude grid: $53-55^{\circ} \mathrm{S}$, $\left.137-143^{\circ} \mathrm{E}\right)$

Anderson DR, Sweeney DJ, Williams TA (1981) Introduction to statistics—an applications approach. West Publishing Company, Minnesota

Bauerfeind E, Nöthig E-M, Pauls B, Kraft A, Beszczynska-Möller A (2014) Variability in pteropod sedimentation and corresponding aragonite flux at the Arctic deep-sea long-term observatory HAUSGARTEN in the eastern Fram Strait from 2000 to 2009. J Mar Syst 132:95-105

Bé AWH, Gilmer RW (1977) A zoographic and taxonomic review of euthecosomatous pteropoda. In: Ramsay ATS (ed) Oceanic micropalaeontology. Academic Press, London, pp 733-808

Bednaršek N, Tarling G, Fielding S, Bakker D (2012a) Population dynamics and biogeochemical significance of Limacina helicina antarctica in the Scotia Sea (Southern Ocean). Deep-Sea Res Pt II 59-60:25-35

Bednaršek N, Možina J, Vogt M, O’Brien C, Tarling GA (2012b) The global distribution of pteropods and their contribution to carbonate and carbon biomass in the modern ocean. Earth Syst Sci Data 4:167-186

Bednaršek N, Tarling GA, Bakker DCE, Fielding S, Jones EM, Venables HJ, Ward P, Kurizan A, Lézé B, Feely RA, Murphy EJ (2013) Extensive dissolution of live pteropods in the Southern Ocean. Nat Geosci 5:881-885

Belkin IM, Gordon AL (1996) Southern Ocean fronts from the Greenwich meridian to Tasmania. J Geophys Res 101: 3675-3696

Berger WH (1978) Deep-sea carbonate-pteropod distribution and aragonite compensation depth. Deep-Sea Res 25:447-452

Bernard KS, Froneman PW (2009) The sub-Antarctic euthecosome pteropod, Limacina retroversa: distribution patterns and trophic role. Deep-Sea Res Pt I 56:582-598

Berner RA (1977) Sedimentation and dissolution of pteropods in the ocean. In: Andersen NR, Malahoff A (eds) The fate of fossil fuel $\mathrm{CO}_{2}$ in the oceans. Plenum Press, New York, pp 243-260

Berner RA, Honjo S (1981) Pelagic sedimentation of aragonite: its geochemical significance. Science 211:940-942

Beszczynska-Möller A, Fahrbach E, Schauer U, Hansen E (2012) Variability of Atlantic water temperature and transport in the entrance to the Arctic Ocean in 1997-2010. ICES J Mar Sci 69:852-863

Betzer PR, Byrne RH, Acker JG, Lewis CS, Jolley RR, Feely RJ (1984) The oceanic carbonate system: a reassessment of biogenic controls. Science 226:1074-1077

Borges AV, Tilbrook B, Metzl N, Lenton A, Delille B (2008) Interannual variability of the carbon dioxide oceanic sink south of Tasmania. Biogeosciences 5:141-155

Bray S, Trull T, Manganini S (2000) SAZ project moored sediment traps: results of the 1997-1998 deployments. Antarctic Cooperative Research Centre report no. 15, Hobart, Tasmania, Australia

Byrne RH, Acker JG, Betzer PR, Feely RA, Cates MH (1984) Water column dissolution of aragonite in the Pacific Ocean. Nature 312:321-326

Caldeira K, Wickett ME (2003) Anthropogenic carbon and ocean pH. Nature 425:365

Collier R, Dymond J, Honjo SM, Francois R, Dunbar R (2000) The vertical flux of biogenic and lithogenic material in the Ross Sea: 
moored sediment trap observations 1996-1998. Deep-Sea Res Pt II 47:3491-3520

Comeau S, Gorsky G, Jeffree R, Teyssie JL, Gattuso JP (2009) Impact of ocean acidification on a key Arctic pelagic mollusc (Limacina helicina). Biogeosciences 6:1877-1882

Comeau S, Jeffree R, Teyssié JL, Gattuso JP (2010a) Response of the Arctic pteropod Limacina helicina to projected future environmental conditions. PLoS One. doi:10.1371/journal.pone. 0011362

Comeau S, Gorsky G, Alliouane S, Gattuso JP (2010b) Larvae of the pteropod Cavolinia inflexa exposed to aragonite undersaturation are viable but shell-less. Mar Biol 157:2341-2345

Comeau S, Gattuso J-P, Nisumaa A-M, Orr J (2012) Impact of aragonite saturation state changes on migratory pteropods. Proc Biol Sci 279:732-738

Cooley SR, Kite-Powell HL, Doney SC (2009) Ocean acidification's potential to alter global marine ecosystem services. Oceanography 22:172-181

Dadon JR, de Cidre LL (1992) The reproductive cycle of the Thecosomatous pteropod Limacina retroversa in the western South Atlantic. Mar Biol 114:439-442

De Bodt C, Van Oostende N, Harlay J, Sabbe K, Chou L (2010) Individual and interacting effects of $\mathrm{pCO} 2$ and temperature on Emiliania huxleyi calcification: study of the calcite production, the coccolith morphology and the coccosphere size. Biogeosciences 7:1401-1412

Dickson AG, Millero FJA (1987) Comparison of the equilibrium constants for the dissociation of carbonic acid in seawater media. Deep-Sea Res 34:1733-1743

Fabry VJ (1989) Aragonite production by pteropod molluscs in the subarctic Pacific. Deep-Sea Res 36:1735-1751

Fabry VJ, Deuser WG (1991) Aragonite and magnesian calcite fluxes to the deep Sargasso Sea. Deep Sea-Res 38:713-728

Fabry VJ, McClintock JB, Mathis JT, Grebmeier JM (2009) Ocean acidification at high latitudes: the bellwether. Oceanography 22:160-171

Feely PA, Sabine CL, Lee K, Berelson W, Kleypas J, Fabry VJ, Millero FJ (2004) Impact of anthropogenic $\mathrm{CO}_{2}$ on the $\mathrm{CaCO}_{3}$ system in the oceans. Science 305:362-366

Francois R, Honjo S, Krishfield R, Manganini S (2002) Factors controlling the flux of organic carbon to the bathypelagic zone of the ocean. Glob Biogeochem Cycles. 1087

Gangst $\varnothing$ R, Gehlen M, Schneider B, Bopp L, Aumont O, Joos F (2008) Modeling the marine aragonite cycle: changes under rising carbon dioxide and its role in shallow water $\mathrm{CaCO} 3$ dissolution. Biogeosciences 5:1057

Gazeau F, Parker LM, Comeau S, Gattuso J-P, O'Connor WA, Martin S, Pörtner H-O, Ross PM (2013) Impacts of ocean acidification on marine shelled molluscs. Mar Biol 160:2207-2245

Gilmer RW, Harbison GR (1986) Morphology and field behavior of pteropod molluscs: feeding methods in the families Cavoliniidae, Limacinidae and Peraclididae (gastropoda: thecosomata). Mar Biol 91:47-57

Gilmer RW, Harbison GR (1991) Diet of Limacina helicina (gastropoda: thecosomata) in Arctic waters in midsummer. Mar Ecol Prog Ser 77:125-134

Gruber N, Gloor M, Mikaloff-Fletcher SE et al (2009) Oceanic sources, sinks, and transport of atmospheric CO2. Glob Biogeochem Cycles. doi:10.1029/2008GB003349

Harbison GR, Gilmer RW (1986) Effects of animal behaviour on sediment trap collections: implications for the calculations of aragonite fluxes. Deep-Sea Res 33:1017-1024

Honjo S, Manganini SJ, Krishfield RA, Francois R (2008) Particulate organic carbon fluxes to the ocean interior and factors controlling the biological pump: a synthesis of global sediment trap programs since 1983. Prog Oceanogr 76:217-285
Howard WR, Roberts D, Moy AD, Lindsay MCM, Hopcroft RR, Trull TW, Bray SG (2011) Distribution, abundance and seasonal flux of pteropods in the Sub-Antarctic Zone. Deep-Sea Res Pt II 58:2293-2300

Hunt BPV, Pakhomov EA, Hosie GW, Siegel V, Ward P, Bernard K (2008) Pteropods in Southern Ocean ecosystems. Prog Oceanogr 78:193-221

Klaas C, Archer DE (2002) Association of sinking organic matter with various types of mineral ballast in the deep sea: implications for the rain ratio. Glob Biogeochem Cycles 16:1116

Langer G, Nehrke G, Probert I, Ly J, Ziveri P (2009) Strain-specific responses of Emiliania huxleyi to changing seawater carbonate chemistry. Biogeosciences 6:2637-2646

Lee C, Hedges J, Wakeman S, Zhu N (1992) Effectiveness of various treatments in retarding microbial activity in sediment trap material and their effects on the collection of swimmers. Limnol Oceanogr 37:117-130

Lenton A, Matear RJ (2007) Role of the Southern annular mode (SAM) in Southern Ocean $\mathrm{CO}_{2}$ uptake. Glob Biogeochem Cycles. doi:10.1029/2006GB002714

Lenton A, Tilbrook B, Law R, Bakker D, Doney SC, Gruber N, Hoppema M, Ishii M, Lovenduski NS, Matear RJ, McNeil BI, Metzl N, Mikaloff-Fletcher SE, Monteiro P, Rodenbeck C, Sweeney C, Takahashi T (2013) Sea-air CO2 fluxes in the Southern Ocean for the period 1990-2009. Biogeosci Discuss 10:285-333

Lewis E, Wallace DWR (1998) Program developed for CO2SYS system calculations. ORNL/CDIAC-105, Carbon Dioxide Information Analysis Center, Oak Ridge National Laboratory, US department of energy, Oak Ridge

Lischka S, Riebesell U (2012) Synergistic effects of ocean acidification and warming on overwintering pteropods in the Arctic. Glob Chang Biol. doi:10.1111/gcb.12020

Lourey MJ, Trull TW (2001) Seasonal nutrient depletion and carbon export in the Subantarctic and Polar Frontal Zones of the Southern Ocean south of Australia. J Geophys Res-Oceans 106:31463-31487

Mackas DL, Galbraith MD (2011) Pteropod time-series from the NE Pacific. ICES J Mar Sci. doi:10.1093/icesjms/fsr163

McNeil BI, Matear RJ (2008) Southern Ocean acidification: a tipping point at 450-ppm atmospheric $\mathrm{CO}_{2}$. Proc Natl Acad Sci USA 105:18860-18864

McNeil BI, Tilbrook B, Matear RJ (2001) The accumulation and uptake of anthropogenic $\mathrm{CO}_{2}$ in the Southern Ocean south of Australia between 1968 and 1996. J Geophys Res 106:3143231445

McNeil BI, Metzl N, Key RM, Matear RJ, Corbiere A (2007) An empirical estimate of the Southern Ocean air-sea CO2 flux. Glob Biogeochem Cycles. doi:10.1029/2007GB002991

Mehrbach C, Culbertson CH, Hawley JE, Pytkowicz RM (1973) Measurement of the apparent dissociation constants of carbonic acid in seawater at atmospheric pressure. Limnol Oceanogr 18:897-907

Meier KJS, Beaufort L, Heussner S, Ziveri P (2014) The role of ocean acidification in Emiliania huxleyi coccolith thinning in the Mediterranean Sea. Biogeosciences 11:2857-2869

Midorikawa T, Inoue HY, Ishii M, Sasano D, Kosugi N, Hashida G, Nakaoka S, Suzuki T (2012) Decreasing pH trend estimated from 35-year time series of carbonate parameters in the Pacific sector of the Southern Ocean in summer. Deep-Sea Res Pt I 61:131-139

Orr JC, Fabry VJ, Aumont O et al (2005) Anthropogenic ocean acidification over the twenty-first century and its impact on calcifying organisms. Nature 437:681-686

Ramsay ATS (1977) Oceanic micropalaeontology. Academic Press, London 
Read BA, Kegel J et al (2013) Pan genome of the phytoplankton Emiliania underpins its global distribution. Nature 499:209-213

Riebesell U, Zondervan I, Rost B, Tortell P, Zeebe RE, Morel F (2000) Reduced calcification of marine plankton in response to increased atmospheric $\mathrm{CO}_{2}$. Nature 407:364-367

Rintoul SR, Bullister JL (1999) A late winter hydrographic section from Tasmania to Antarctica. Deep Sea Res I 46:1417-1454

Roberts D, Howard WR, Moy AD, Roberts JL, Trull TW, Bray SG, Hopcroft RR (2011) Interannual pteropod variability in sediment traps deployed above and below the aragonite saturation horizon in the Sub-Antarctic Southern Ocean. Polar Biol 31:1739-1750

Sabine CL, Feely RA, Gruber N et al (2004) The oceanic sink for anthropogenic $\mathrm{CO}_{2}$. Science 305:367-371

Seibel BA, Dierssen HM (2003) Cascading trophic impacts of reduced biomass in the Ross Sea, Antarctica: just the tip of the iceberg? Biol Bull 205:93-97

Smith TM, Reynolds RW (2004) Improved extended reconstruction of SST (1854-1997). J Climate 17:2466-2477. Data: http:// www.ncdc.noaa.gov

Sokolov S, Rintoul SR (2002) Structure of Southern Ocean fronts at $140^{\circ}$ E. J Mar Syst 37:151-184

Steinacher M, Joos F, Frölicher TL, Plattner GK, Doney SC (2009) Imminent ocean acidification projected with the NCAR global coupled carbon cycle-climate model. Biogeosciences 6:515-533

Takahashi T, Sutherland SC et al (2009) Climatological mean and decadal change in surface ocean pCO2, and net sea-air $\mathrm{CO} 2$ flux over the global oceans. Deep-Sea Res Pt II 56:554-577

Trull T, Bray S, Manganini S, Honjo S, Francois R (2001a) Moored sediment trap measurements of carbon export in the SubAntarctic and Polar Frontal zones of the Southern Ocean, south of Australia. J Geophys Res 106:31489-31510
Trull TW, Rintoul SR, Hadfield M, Abraham ER (2001b) Circulation and seasonal evolution of polar waters south of Australia: implications for iron fertilisation of the Southern Ocean. DeepSea Res Pt II 48:2439-2466

Trull TW, Sedwick PN, Griffiths FB, Rintoul SR (2001c) Introduction to special section: SAZ Project. J Geophys Res 106:31425-31430

Trull TW, Schulz EW, Bray SG, Pender L, McLaughlan D, Tilbrook B (2010) The Australian integrated marine observing system Southern Ocean time series facility. OCEANS 2010 IEEE Sydney Conference. doi:10.1109/OCEANSSYD.2010.5603514

van der Spoel SVD (1967) Euthecosomata a group with remarkable developmental stages (gastropoda, pteropoda) zoological museum, Amsterdam

van der Spoel S, Dadon JR (1999) Pteropoda. In: Boltovskoy D (ed) South Atlantic zooplankton. Backhuys Publishers, The Netherlands, pp 649-706

van der Spoel S, Newman LJ, Estep KW (1997) Pelagic molluscs of the world: ETI world biodiversity CD-ROM series-version 1

Walczowski W, Piechura J (2007) Pathways of the Greenland Sea warming. Geophys Res Lett. doi:10.2029/2007GL029974

World ocean atlas (2012) http://iridl.ldeo.columbia.edu/SOURCES/. NOAA/.NODC/.WOA09/.Grid-1x1/.Monthly/ Accessed 7 Mar 2012

Yoshikawa-Inoue $\mathrm{H}$, Ishii $\mathrm{M}$ (2005) Variations and trends of $\mathrm{CO}_{2}$ in the surface seawater in the Southern Ocean south of Australia between 1969 and 2002. Tellus 57B:58-69

Zar JH (1972) Significance testing of the Spearman Rank correlation coefficient. J Am Stat Assoc 67:578-580 